\title{
SEXO FEMENINO: SECRETOS COMPARTIDOS DE MADO MARTÍNEZ
}

\author{
FEMALE SEX: SHARED SECRETS BY MADO MARTÍNEZ
}

Mercedes Arriaga Flórez

Universidad de Sevilla

\section{Resumen:}

Mado Martínez en sus cuentos construye un universo paralelo en el que los hombres no existen. Una genealogía femenina sustituye al sistema patriarcal. Hay personajes que muestran una lógica en el delirio femenino. Las mujeres en sus obras son mujeres capitanas de sí mismas que no temen las restricciones o las prohibiciones. No faltan la suspense y seres como hadas y brujas.

\section{Palabras claves:}

Mujeres, Mado Martìnez, independencia.

\section{Abstract:}

Mado Martinez builds in his works a parallel universe where men don't exist. A feminine genealogy replaces the patriarchal system. Some characters show some logic in the feminine delirium. The women in his works are their own leaders and they are not afraid of restrictions or prohibition. Suspense and magical creatures such as fairies and witches can be found in his works.

\section{KEY WORD:}

Women, Mado Martìnez, indipendence. 
"Una mujer necesita que la amen, no que la alaben y la reduzcan a un icono" Maria Marchesi

Secretos compartidos de Mado Martínez (2007) nos confirma, si hiciera falta y en contra de otras opiniones autorizadas, que SÍ tenemos un sexo, y que además nuestro sexo no es el segundo sexo, sino nuestro único, primero y primordial sexo, o como le gusta decir a Alda Merini, poeta italiana contemporánea, nuestro útero, es además el órgano básico del pensamiento y de la creación, porque "las ingles son también la fuerza del alma" (Merini, ${ }^{* * *}$ ).

El sexo femenino se convierte en los cuentos de Mado Martínez en el "cofre más íntimo y profundo que albergan los tesoros de su cuerpo" (Martínez 2007: 91) o en "la lámpara mágica de la que brotaba el deseado manantial" (Martínez, 2007: 50). Es decir, estamos ante la sexualidad que constituye la base de lo que Judith Butler llama una "filosofía de la encarnación" (Butler, 1993), que a través del género realiza un proceso de interpretación y renovación de la cultura. Estamos ante cuerpos que cuentan, en el doble sentido de que son importantes en sí, en su materialidad, antes pasada inoservada, y además tienen historias nuevas que contar. Secretos compartidos coloca el tema del sexo femenino, en esa dimensión de reinvindicación de la mujer-sujeto femenino universal que a su vez se propone reconducir a las mujeres a su propia historia, o mejor a su propia deshistoria. La encarnación de los personajes femeninos en cuerpos femeninos a través de una sexualidad lesbiana conducirá a su colocación en un campo material y simbólico de sentido, como dice Donna Haraway (1988) que producirá una epistemología, unos saberes en los que toda una comunidad podrá verse reflejada. En el prólogo la autora especifica así sus intenciones con respecto a la materia ficcional que va a acometer:

"Conquistar y reconquistar las voces lesbianas que durante milenios han estado selladas en el olvido, como islas enterradas en el fondo del mar que, de repente, emergen denuevo, desterrandola tierra del mundo que las había estado oprimiendo desde la superficie" (Martinez, 2007: 14).

Este propósito contiene en sí los dos aspectos fundamentales que conforman la identidad femenina: la relación de la totalidad del género con la individualidad de cada mujer, es decir, lo que las mujeres tenemos en común, y al mismo tiempo las diferencias y especificidades de cada vida singular e individual. Estos relatos, como muchas otras novelas, muestra que la sexualidad femenina no es uniforme ni homogénea, que se puede ser una mujer o muchas mujeres diferentes sin dejar por ello de ser mujer. La reflexión de fondo es la no aceptación de los límites de lo femenino tal y como han sido trazados por el sistema patriarcal. Unos límites tan estrechos que habían llevado a Monique Witting a decir provocatoriamente que las lesbianas "no eran mujeres" (1980) y antes que ella, ya Sor Juana Inés de la Cruz, había puesto el dedo en la yaga cuando en uno de sus versos decía que ella no era mujer porque no "servia de mujer a nadie". En estas páginas se reflexiona sobre lo que significa ser mujer sin preposiciones. Mujer para si misma. Mujer como vocablo intransitivo, robándole la metáfora a Roland Barthes.

Narrativamente este intransitividad se construye a través de historias que no practican el enfrentamiento con el sistema patriarcal, sino su sustitución, que es también una forma de subversión, y que giran en torno a dos principales temas:

La excelencia de las mujeres y la construcción de una genealogía femenina

La solidariedad o sororidad entre mujeres que construyen comunidades-gineceos

Mado Martínez construye un universo paralelo en el que los hombres están ausentes, están silenciados, no existen, como dice Renée Vivien, protagonista de uno de ellos:

“¿Qué importan los hombres? No importaban nada! Los hombres no existen! (Martínez, 2007: 134).

Sus relatos son abyectos en el sentido que da a esta palabra Julia Kristeva como aquello "que perturba la identidad, el sistema, el orden. Aquello que no respeta las fronteras, las posiciones, los roles" (Kristeva, 1980: 12). El trastocamiento del deseo (obvio y masculino), y la sustitución del cuerpo deseante, conlleva una inversión en los simbólico que abre la puerta a historias todavía no imaginadas o no contadas:

"El hada madrina fue entonces a ver a la bella durmiente y le explicó los motivos por los que no tenía que atormentar al dragón que ya estaba tan viejo y desvalido. Pero la bella durmiente, absorta en sí, y sin atender lo que le decían, confundió el hada madrina con la princesa de sus sueños y le dijo: "Ahora tú me besarás en los labios, princesa. ¿Has matado ya al príncipe malvado para entrar aquí? (Martínez, 2007: 165)

Como se corresponde a todo sexo escondido durante mucho tiempo, los relatos de Mado Martinez sólo podían presentarse como "secretos compartidos", un título que hace hincapié en esa doble vertiente de lo personal e intransferible y lo colectivo y compartido. El secreto es siempre comprometedor para el que lo recibe y para quien lo dona, el secreto crea complicidad, pide confianza en cambio de dejarse ver sin protección. El secreto ofrece sinceridad pero pide adhesión, pide participación, por eso Mado nos convierte a todas sus lectoras en aliadas, en cómplices, en participantes, capturándonos en un juego en donde lo que se escribe y lo que se lee se barajan como cartas. Mado va tejiendo sus historias de manera que quedamos capturadas en su laberinto de espejos, de forma que al final también vemos nuestro rostro en sus letras. De hecho la metáfora del espejo, del doble está por todas partes: en la historia de los gemelos de Aspis, en la que al final ella es él y él es ella, en la historia de las dos Piratas 
del mismo nombre que levan anclas, etc, pero sobre todo en la concepción del deseo y del amor hay una aspiración a ese "iguales", que subraya la reciprocidad en contra la desigualdad de las relaciones heterosexuales, en las que los hombres son únicos dueños de los medios de producción del placer:

“-Abu Ra Sada tiene los pechos más bellos del mundo, mi reina. Un hombre podría desfallecer de amor sólo si pudiera mirarlos- dijo Polilla

-Y para qué quiero yo que un hombre desfallezca de amor por mis pechos si no tiene pechos por los que yo pueda desfallecer de amor- apostilló la reina con seriedad" (Martínez, 2007: 36).

Como sugiere Luisa Muraro, el nexo entre placeres y saberes sólo puede sugerirse a través de la "deformidad del lenguaje" de su "inexorable desequilibrio" (Muraro, 1998: 192-193). El punto de vista metafórico queda sustituido por el metonímico, es decir, se abandona lo que se considera verdad, normal, justo para sustituirlo por el contenido concreto de nuestra experiencia en el mundo. Yo no creo que sea casualidad que este libro empiece con un relato de infancia, un relato de alguna forma de iniciación al erotismo entre dos amigas. Ese relato es un incipit que hunde sus raíces en la infancia y que constituye uno de esos episodios que marcan al personaje, en los que la vida nos revela nuestra propia esencia interior.

“La mirada de Norma se quedó atrapada en los muslos blancos que aquellos cuadros escoceses de la falda de Marina permitían ver en esa circunstancia. Tuvo deseos de tocarlos con urda de María nenten dí por qué pero tenía nia. Tuvo de hacerlo La liea la a de hacerlo. La idea la acaloraba cada vez más pero era un calor agradable del que no quería desprenderse; cedio a su impetu deslizando su mano y un leve mareo seguido de agradable cosquilleo invadió todo su cuerpo" (Martínez, 2007: 29).

El personaje de Mado parece seguir el consejo que Luce Irrigary da al final de su libro Este sexo que no es un sexo, en el que dice que hacer las cosas de las que se tiene gana, sin "válida causa", "sin justificaciones”, es la única naturaleza que hay que seguir (Irrigaray, 1977: 168 y169).

Me gusta el principio que establece Mado en este libro: “En principio fue el deseo”, después vino o viene todo lo demás. Y me gusta por dos motivos: porque coloca nuestra razón (pasional) de ser, dentro de nosotras mismas y no fuera, en lo que significamos como mercancías de uso o mercancías de intercambios entre hombres y, dos, porque esa razón pasional nos hace dignas herederas de tantas mujeres que la han defendido, contra otras razones más lógicas dicen. Como decía Carmen, la cigarrera de la Fábrica de Tabaco de Sevilla, "primero el amor y después el trabajo", y después le contesta en un eco la escritora Sibilla Aleramo desde Italia con su novela "Amo, luego existo".

Entre todos los personajes que pueblan este libro de relatos hay dos que se insertan de lleno en está lógica del delirio femenino. Una es, como no iba a serlo, Safo. Estandarte de los valores femeninos en contra de los masculinos: "el valor está en amar", dice Safo, el heroísmo no sirve de nada, en un eco de Angeles Mastreta que afirma siempre que el heroísmo es la incitación al asesinato. El otro personaje femenino es René Vivien, que en cambio encarna el lado oscuro de la mujer fatal. Mado Martinez es muy hábil en estos dos relatos, trasformando en prosa todos los poemas de Safo, sobre todo los que describen los efectos del amor, y reconstruyendo para nosotras pensamientos y sentimientos de la intimidad de René Vivien. Mado cumple así para nosotras una especie de sueño de la intimidad, en el que el discurso autobiográfico se ensancha.

Dos figuras femeninas Safo y René Vivien que son como dos matrioskas que recogen dentro de sí todas las imágenes de lo femenino, lo femenino angelical y lo femenino tortuoso a demostración de que no existe ninguna naturaleza femenina predeterminada. De hecho también para las mujeres el amor a veces tiene más que ver con la antropofagia y la intrusión que con los buenos sentimientos, porque el amor está abierto a todas las circunstancias y no somos nosotros las que lo controlamos, todo lo más a veces nos lleva a rastras. En el amor, las mujeres no tienen porque ser las victimas, las abandonadas, las resignadas, la perseguida, la deseada sino todo lo contrario o ambas cosas al mismo tiempo. Una movilidad de roles que se concentra en la metáfora erótica de la caza:

"Hundió su cabeza cubriendo el triángulo de aquella geometría de posibilidades infinitas como si de una pantera hurgando entre las vísceras deliciosas de sus víctima se tratara" (Martínez, 2007: 92).

Como sostiene Fatima Mernisi en uno de sus libros, el amor puede convertirse en una prisión y puede devorarnos. Por eso las mujeres tenemos que estar siempre alertas. Lo que está en juego en estas páginas es, por una parte, la exhibición-proclamación del deseo femenino, durante demasiado tiempo exclusiva masculina, y por otra, la recuperación-exploración del cuerpo femenino, durante demasiado tiempo negado. Hay en el fondo una discusión es la naturaleza de los aphrodisia, es decir de los placeres, gestos, actos y roces que proporcionan placer. No olvidemos que estamos ante un erotismo "contra natura", como lo había definido Platón en sus Leyes, que une mujer con mujer y que precisamente surge, dice Platon, de la falta de la "desmesura", del exceso. Si la lujuria, en sentido platónico, es una enfermedad del cuerpo que "reduce" (esta es la palabra que utiliza Platón, y que yo sustituiría por agranda), el individuo "al exceso de placer y de dolor" (Platon, Timeo), en contraposición la temperanza, significa control sobre placeres y pasiones, e implica orden y dominio. No hace falta especificar cual de estos dos principios se corresponden con lo femenino y lo masculino porque es obvio y evidente y hasta puede que sea una ventaja que nos toque la lujuria, como se insinua en estas páginas. 
Podemos decir entonces que la falta de medida en la unión entre mujeres anula también los dos principios masculino-activo y femenino-pasivo como agentes de la escena erótica, anula la barrera de la diferencia sexual para en cambio favorecer su con-fusión. La ausencia de límites en la naturaleza de la mujer es un topos bien conocido. En la literatura erótica escrita por hombres aparece como insaciable, o en su extremo opuesto como insensible, frígida, inanimada, en la literatura idealizadora que proclama la mujer-ángel, la mujer sin cuerpo y sin carne. Los personajes que Mado Martínez construye escapan de la lógica de la temperanza y del control que la mujer debe observar en dos sentidos, en referencia a la institución que representa, como madre de, hija de, esposa de, y en referencia a su yo íntimo, donde se anula relación de dominio y superioridad que se corresponde con el principio de la virilidad. Las mujeres de Mado obvian ambas referencias por ser dos referencias a la subordinación femenina, una en sentido social, sometida al orden patriarcal de la familia y la otra en sentido moral, donde lo femenino debe ser controlado por el principio masculino de la racionalidad y el orden. De muestra, la escena de la reina que come dátiles mientras se enamora de su esclava:

"Solo había tenido que abrirla de piernas y frotar con delicadeza la pulpa del dáti contra otra pulpa. Definitivamente era mejor de lo que había esperado hallar: no sólo sabía mejor, sino que había ganado una gran virtud más para sus sentidos: olía a delirio" (Martínez, 2007: 50).

El olor-sabor es uno de los sentidos principales que se despliegan en éstas páginas y que corre paralelo a la locuacidad de las mujeres cuando hacen el amor, que lejos de permanecer mudas en el acto refuerzan el erotismo con palabras pronunciadas para añadir música a la escena. Estos sentidos, oído, gusto, olfato se alían para destruir la concepción del deseo y del sexo femenino como enigmáticos y para concederle una concreción material.

Dice Safo de los encantos de su amada: "Que bien sabe dioses, que bien sabe, que bueno que está. Es el manjar que me comería todas las noche junto al fuego" (Martínez 2007: 92). El desplegamiento del deseo femenino nos conduce a esa pansexualidad que Luce irrigaría proclama para el erotismo femenino y a la que le hace eco Elene Cixous: "Yo soy mujer. Escribo como la que soy. ¿Cómo podría yo ser mujer por una parte y por otra escribir? Todo mi cuerpo es sexuado. Mi sexualidad no acaba en mi sexo o en el acto sexual (en sentido estricto)" (Irrigaray, 1992: 51). La sexualización de la naturaleza, que en autores como Baudelaire toma proporciones de antropomorfizacion de paisajes naturales, con acento sobre las zonas erógenas, en estos cuentos se centra más que en paisajes, en frutos de la naturaleza que revisten en sí una carga sexual simbólica. Más que el tema de la forma gigantesca o el tema de la naturaleza despiadada o la monstruosidad, se trata el tema de lo minúsculo, como el del capítulo de los dátiles de la reina, o de la naturaleza aliada:

“Pero ella no veía en el viento más que el aliento fresco de una mujer a la que se empeñó en querer demasiado. Si dejaba su mirada perdida en el río, la recordaba a ella nadando en la playa; si oía los pájaros, oía su voz. Probablemente. Aún habiendo huido al polo norte o al desierto habría encontrado que la arena y nieve le recordaban inevitablemente, a ella" (Martínez, 20007: 66).

Es muy significativo que en este cuento precisamente la muerte se presente a la protagonista sin ninguno de sus atributos de horror, al contrario, lo hace como una amiga que invita a la protagonista a dar un paseo por el reino del más allá, y que se titule precisamente la Xiana del Cares, una figura de la mitología asturiana heredera de la Gran madre que encarna a la mujer-naturaleza, figura del agua y de la identidad fluida.

Dice Virginia Wolf que las mujeres no tenemos patria, y Eleonora Dussen decía que nuestro país preferido es la travesía, Margarita Duras quería vivir sin identidad y Alda Merini y Mado Martinez desean abitar todas las posibles identidades, intercambiar sus corazones con el de otras mujeres, siendo todas y siendo única. Dice cierta filosofía de las mujeres que somos un pluralis que no tiene singular, para decir que todas las mujeres somos iguales y tenemos la misma esencia (naturalmente esa esencia que otros han escogido y decidido otros que tenemos), bueno pues sí somos un pluralis pero no indiferenciado, porque cada mujer puede ejercer con su vida la posibilidad de la insurrección, de la sospecha. Puede volver del revés y cuestionar todo lo que la cultura le ha puesto encima como una capa de barniz que no deja transpirar ni respirar al ser. Tantas mujeres antes que nosotras han desafiado a ese plural indiferenciado y nosotras no queremos dejar de reflejarnos en sus palabras, en sus actos, en sus vidas. Es por eso que los personajes de Mado no son seres hechos y derechos con una identidad rígida sino seres en train de ser, seres abiertos al mundo y a sus trasformaciones: una reina que se vuelve esclava, una pescadora que termina pescada por la dama de la muerte, un tranzado de figuras femeninas que se miran y se admiran unas en otras. Mado resucita el valor de las amigas, el coraje de las amantes, la fidelidad de las compañeras de armas, porque la solidaridad femenina no es una quimera, el valor del conocernos y reconocernos. Dice Maria Zambrano que la confesión revela los conatos del ser, su verse en con-fusión con el mundo, su verse en com-pasion o colisión con él. Todos los personajes femeninos que desfilan por estas páginas están impregnados de pasión, de valor, mujeres que toman el timon de su propia nave, mujeres capitanas de sí mismas que no temen las restricciones o las prohibiciones, mujeres que se atreven a soñar $\mathrm{y}$ a soñarse en mundos diferentes, mujeres que hablan con las flores y trastocan los 
personajes y las identidades de las malas historias en las que no nos reconocemos "érase una vez una princesa que amaba a una princesa".

La reescritura de los cuentos de hadas en clave femenina prevé en cuentos como el de La profecía que la bruja huya con la princesa. Este tipo de reescritura constituye además una forma de sexualización de la lengua y de sus formas escritas, que privilegia las genealogías femeninas, en contra de las masculinas y sus códigos lógicos. Por ese motivo quizás los escenarios de estos cuentos reconstruyen un mundo mítico, alejado de la cotidianeidad que aprisiona a las mujeres en sus roles de madres y esposas y las reduce al espacio de lo doméstico. La utopía matriarcal se coloca en el marco de lo extraordinario, ese espacio libre en el que heroísmo y erotismo femeninos pueden darse la mano.

Mado sabe muy bien cómo construir la supense, el misterio aprovechando todos los aspectos que la cultura patriarcal ha atribuido a lo femenino. Sus personajes viven en esa ambigüedad de seres maravillosos y al mismo tiempo siniestros, a caballo entre las hadas y las brujas. Porque es allí, en la naturaleza contradictoria de lo femenino en donde se coloca la escritora para crear, y donde nos colocamos todas las mujeres para sobrevivir.

Quiero terminar con las palabras de Dora Russell, que decía que "para nosotras el cuerpo no es un mero continente del alma, sino un templo de placer y éxtasis. Un templo para abrazar el futuro si es necesario" (Russell, 2005: 60). Yo creo que es muy necesario, porque todo lo que concierne a nuestro deseo y a nuestro cuerpo todavía se está escribiendo.

\section{REFERENCIAS BIBLIOGRÁFICAS}

Almansi, G., L'estetica dell'osceno. Per una letteratura canivalista, Einaudi, Turín, 1974.

Butler, J., Corpi che contano, Feltrinelli, Milán, 1993.

Foucault, M., L'uso dei piaceri, Feltrinelli, Milán, 2004.

Haraway, D., "Situated Knowledge: the Science Question in Feminim as a Site of Discourse on

the Privilege of Partial Perspectiva", en Feminist Studies, 14, 3, 1988.

Irigaray, L., Questo sesso che non è un sesso, Milán, Feltrinelli, 1977.

----, Yo, tú, nosotras, Madrid, Cátedra, 1992, p. 51.

Kristeva, J., Pouvoirs de l'horreur, Senil, Paris, 1980.

Martínez Muñoz, M., Secretos compartidos, Odisea, Madrid, 2007.

Muraro, L., Maglia o uncinetto, Manifestolibri, Roma, 1998.

Russell, D., Hipatia, KRK, Oviedo, 2005.
Wittig, M., «El pensamiento heterosexual», en El pensamiento heterosexual, Barcelona, Egales, 2005. 